\title{
GAMBARAN KEPRIBADIAN GELAP (DARK TRIAD PERSONALITY) PADA PENGGUNA MEDIA SOSIAL
}

\author{
Irfani Rizal ${ }^{1}$ dan Benni Handayani ${ }^{2}$ \\ ${ }^{1}$ Program Studi Psikologi, Fakultas Psikologi, Universitas Islam Riau, Pekanbaru, Indonesia. \\ ${ }^{2}$ Program Studi Komunikasi, Fakultas Komunikasi, Universitas Islam Riau, Pekanbaru, Indonesia. \\ Email: irfanirizal27@psy.uir.ac.id
}

\begin{abstract}
Nowadays, humans today are inseparable from the sophistication of information and communication technology, all people can enjoy the sophistication of today's technology, be it children, adolescents, adults, and even parents who cannot be separated from technology. In Indonesia, the age range is from 15 years to 24 years and is the largest user. The sampling technique used in this study was purposive sampling. The research subjects were 386 respondents and were active social media users. The measuring instrument used in this study uses an adaptation scale of dark triad personality by Jones and Pauhlus (2014) which consists of 26 items that the authors translate and adapt to the Indonesian culture. The purpose of this study was to describe the dark triad of personality among social media users. A dark personality is a personality that is dominated by negative behavior. The results showed 15.80\% had high traits of Machiavellianism, 14.76\% had high traits of narcissism, and $15.02 \%$ had high traits of psychopathy. Based on the results of the analysis of the mean value of personality factors based on the dark triad personality theory, it can be concluded that in general, the highest mean value is on the trait of Machiavellianism with a mean value of 21.09 and the lowest score lies in the characteristics of psychopathy, namely 11.20. Most social media users are Instagram with a percentage of $95.5 \%$ then Instant Massaging (Wa / Line) at $83.8 \%$ and Facebook at $53 \%$. The dark personality or dark triad personality is a personality that is dominated by negative behavior so that in the Islamic perspective it is included in the personality of anger, which means that the individual tends to the character of the body and teaches the principle of enjoyment.
\end{abstract}

Keywords: Dark Triad Personality, Machiavellianism, Narcissism, Psychopathy, Social Media

\begin{abstract}
ABSTRAK
Tidak bisa dipungkiri, manusia sekarang tidak terlepas dari kecanggihan teknologi informasi dan komunikasi, semua kalangan dapat menikmati kecanggihan teknologi masa kini. Di Indonesia pengguna internet terbesar berada pada rentang usia 15 tahun sampai 24 tahun. Purposive sampling merupakan metode pengambulan sampel pada penelitian ini. Subjek penelitian berjumlah 386 responden dan merupakan pengguna media sosial secara aktif. Skala penelitian menggunakan skala adaptasi dark triad personality oleh Jones and Pauhlus (2014) yang terdiri dari 26 aitem yang penulis terjemahkan dan sesuaikan dengan budaya Indonesia. Tujuan dilakukannya penelitian ini adalah untuk melihat gambaran dark triad personality pada pengguna media sosial. Kepribadian gelap atau dark triad personality merupakan kepribadian yang didominasi pada tingkah laku negatif. Hasil penelitian menunjukkan $15.80 \%$ tinggi pada kepribadian machiavellianism, $14.76 \%$ berada pada traits narcissism tinggi, dan $15.02 \%$ memiliki kepribadian psychopathy tinggi. Berdasarkan nilai mean dari kepribadian gelap maka dapat disimpulkan bahwa, secara umum kepribadian machiavellianism memiliki nilai mean tertinggi dengan nilai mean sebesar 21.09 dan skor terendah terletak pada traits psychopathy yaitu sebesar 11.20. Pengguna media sosial terbanyak adalah Instagram dengan persentase sebesar 95.5\% kemudian Instant Massaging (Wa/Line) sebesar $83.8 \%$ dan Facebook sebesar 53\%. Kepribadian gelap atau dark triad personality merupakan kepribadian yang
\end{abstract}


didominasi pada tingkah laku negatif, sehingga dalam perspektif Islam termasuk dalam kepribadian ammarah yang berarti individu tersebut cenderung mengejar prinsip kenikmatan.

Kata Kunci: Kepribadian gelap, Machiavellianisme, Narsisme, Psikopati, Media Sosial

\begin{tabular}{|c|c|c|c|}
\hline FIRST RECEIVED: & REVISED: & ACCEPTED: & PUBLISHED: \\
09 September 2020 & 06 November 2021 & 11 April 2021 & 28 April 2021 \\
\hline
\end{tabular}

\section{PENDAHULUAN}

Tidak bisa dipungkiri, saat ini teknologi informasi semakin maju, canggih dan berkembang dalam kehidupan manusia. Semua kalangan dapat menikmati kecanggihan teknologi masa kini. Telepon seluler merupakan teknologi informasi dan komunikasi yang paling sering digunakan untuk saat ini.

Prevelensi penggunaan internet sampai dengan tahun ini semakin tinggi, berdasarkan survey Asosiasi Penyelenggara Jasa Internet Indonesia (APJII) jumlah penduduk Indonesia di tahun 2019 sebanyak 264.16 juta yang artinya bahwa lebih dari setengah dari total penduduk Indonesia aitu lebih kurang 171.17 juta orang telah dapar menikmati jaringan internet

Berdasarkan survey APJII (2019) menjelaskan bahwa $72.41 \%$ yang menggunakan jasa internet berasal dari perkotaan, serta rentang usia 15 tahun hingga 24 tahun merupakan pengguna internet terbanyak yang berjumlah lebih kurang 49.52\%. Dalam hal ini berarti pengguna terbanyak dalam mengakses internet berada pada kategori remaja dan dewasa awal.

Menurut Reed (2016) mengatakan bahwa masa remaja ialah masa yang ditandai dengan keinginan untuk mendapatkan kebebasan, mengeksplorasi keyakinannya tentang dunia, dan menumbuhkan persahabatan yang erat. Selanjutnya, menurut Santrock (2012) memapaparkan bahwa remaja ingin diterima di kalangan teman sebayanya.

Beberapa penelitian menjelaskan dampak positif penggunaan internet yaitu dapat memperkaya anak dengan ilmu pengetahuan, meningkatkan rasa ingin tahu mereka terhadap belajar dan anak menjadi kreatif serta berintelektual, Beberapa pemanfaatan lainnya dalam pengguna internet yaitu dapat membeli barang secara online, memesan transportasi online serta juga dapat berbisnis dan berkarya melalui internet (Bohang, 2018; Quarshie, 2012).

Faktor kepribadian merupakan salah satu penentu dari perilaku seseorang. Kepribadian dapat diartikan sebagai seperangkat karakteristik yang cenderung stabil yang menentukan 'perbedaan tingkah laku seperti berpikir, gerakan dari seseorang dengan durasi waktu yang lama serta tidak mudah untuk dapat dipahami (Alwisol, 2016). Berdasarkan definisi tersebut maka dalam kepribadian tidak ada yang benar ataupun yang salah, tetapi berada pada kecenderungan seseorang dalam berperilaku atau terlihat dalam suatu tingkah laku yang sering muncul. Salah satu jenis kepribadian yang belum banyak di teliti khususnya pada pengguna media sosial yaitu dark triad personality. Dark Triad Personality. Pada tulisan Goodboy et al (2015) yang termasuk dalam kepribadian gelap adalah Machiavellianism, Narcissism, dan Psychopathy. 
Berdasarkan fenomena yang terjadi, remaja sangat rentan dalam kecenderungan melakukan tingkah laku negatif yang di prediksi dari Dark Triad Personality yakni Machiavellianism, Narcissism, dan Psychopathy serta untuk mengetahui prediksi dari masing-masing kepribadian dalam memprediksi tingkah laku penggunaan media sosial pada remaja.

\section{Dark Triad Personality}

Menurut (O'Boyle et al., 2012) salah satu teori yang menjelaskan tentang Dark Triad atau kepribadian gelap atau disebut juga dengan tiga kepribadian "sisi gelap" saling berkaitan satu sama lain yang berfokus kepada tiga traits yaitu machiavellianism, narcissism, dan psychopathy mengartikan juga bahwa ketiga traits ini memiliki tingkatakn keburukan atau kejelekan yang akan berpengaruh kedalam perilaku sesorang

Kepribadian machiavellianism merujuk pada kecenderungan untuk memanipulasi orang lain. Teori yang dikemukakan oleh peneliti Lyons (2019) Traits machiavellianism dapat dicirikan beberapa karakteristik yang terdiri dari tiga hal yang berkaitan. (1). Ketika berkomunikasu dan berurusan dengan orang lain, traits ini suka melakukan tindakan manipulatif (2). Berpandangan dengan sinis terhadap sifat bawaan manusia serta (3) Berpandangan bahwa mencari keuntungan terlepas melampaui prinsip-prinsip hidup.

Penilaian diri secara berlebihan merupakan ciri khusus dari traits narcissm. Beberapa hal yang menjadi ciri atau karakteristik narcissm yaitu berpendangan secara berlebihan tentang pribadi sendiri, fantasi terhadap kontrol, memiliki anganangan atau imajinasi yang tinggi terhadap suatu keberhasilan, merasa kagum secara berlebihan kepada diri sendiri, merasa mencintai diri sendiri secara kuat dan berlebih serta ingin diperkuat oleh orang lain. Seseoarang yang memiliki traits narcissm juga lebih sering untuk membanggakan prestasi secara berlebihan, cenderung tidak menerima kritikan, tidak mau untuk diajak berkompromi atau kerjasama, dan mencari hubungan dengan orang lain yang hanya merasa kagum dengan kelebihan yang mereka punya merupakan pemaparan dari jurnal (O’Boyle et al., 2012). Sedangkan, jika dilihat dari pendapat orang lain maka seseaorang yang narsis ini akan terlihar sombong yaitu dengan cara mempromiskan diri sendiri, agresif dan kebanyak mereka kurang disenangi oleh otrang lain dengan sifatsifatnya. Dalam beberapa kasus juga terkait dengan agresi. Kepribadian narcissism biasanya menolak umpan balik negatif, tetapi jika dikecam atau dikritik oleh orang lain, maka akan cenderung merespons secara agresif.

Salah satu tulisan menjelaskan Sbarbaro (2011) Individu dengan psychopathy mengacu pada kecenderungan individu terhadap rendahnya rasa empati, terlibat dalam perilaku impulsive dan suka mencari sensasi. Trait's psychopathy dicirikan sebagai seseorang yang kurang empati dan peduli dengan orang lain dan juga ketika bersalah mereka cenderung untuk tidak merasa menyedal dengan perbuatannya. Secara emosional tidak peka, mereka sering membebani orang lain, terlibat dalam berbagai kegiatan kriminal untuk mencapai tujuan tertentu. Psychopathy awalnya didiagnosis sebagai suatu gangguan klinis, secara khususs sering disebut sebagai gangguan anti sosial. Tetapi penelitian terbaru mengungkapkan bahwa ternyata psychopathy dianggap sebagai suatu personality traits. 


\section{METODE PENELITIAN}

Kuantitatif deskriptif digunakan dalam metode penelitian ini yakni dengan menyebarkan kuesioner. Skala yang digunakan adalah skala Dark Triad Personality menggunakan skala adaptasi dari penelitian sebelumnya (Jones dan Pauhlus, 2014). Skala Triad Dark Personality di terjemahkan terlebih dahulu ke bahasa Indonesia oleh dua lembaga pusat bahasa, kemudian disesuaikan dengan budaya Indonesia oleh expert judgement dan uji bahasa sesuai dengan kriteria sampel yang telah ditentukan pada sampel penelitian.

Purposive sampling digunakan sebagai teknik pengambilan data dalam penelitian ini dengan kriteria subjek penelitian adalah: 1). Berusia 15-24 tahun 2). Aktif menggunakan media sosial 3). Berdomisili di Pekanbaru. Adapun jumlah subjek pada penelitian ini sebanyak 386 orang berdasarkan dari tabel Krejie dengan melihat taraf kesalahan sebesar 5\%.

\section{HASIL DAN PEMBAHASAN}

Adapun jumlah responden penelitian yakni sebanyak 386 partisipan. Yang terdiri dari responden laki-laki yakni sebanyak 81 orang dan responden perempuan sebanyak 305 orang. 193 responden berusia pada rentang 18-20 tahun, 163 responden berusia 21-24 tahun dan 30 responden berada pada rentang usia 15-17 tahun. Secara keseluruhan, terlihat bahwa media sosial yang paling banyak dan yang menjadi favorit pengguna internet adalah pengguna Instagram sebanyak 371 responden, selanjutnya WhatsApp dan Line, yaitu sebanyak 326 responden, diikuti dengan Facebook 200 responden, twitter 142 responden, youtube 74 responden dan media sosial lainnya 68 responden. Adapun durasi menggunakan media sosial dalam satu hari kebanyakan responden menghabiskan waktu 3-6 jam sebanyak 163 responden, diikuti sebanyak 96 responden dengan durasi menggunakan media sosial >8jam, 66 responden dengan durasi menggunakan media sosial 6-8 jam dan 61 responden dengan durasi menggunakan media sosial 1-3 jam dalam satu hari. Berikut data responden pada penelitian ini :

Tabel 1. Deskripsi Responden Penelitian

\begin{tabular}{cccc}
\hline Demografi & Karakteristik & Frekuensi & Persentase $\%$ \\
\hline Jenis & Laki-Laki & 81 & $20.8 \%$ \\
Kelamin & Perempuan & 305 & $79.2 \%$ \\
& $15-17$ & 29 & $7.5 \%$ \\
Usia & $18-20$ & 193 & $49.6 \%$ \\
& $21-24$ & 163 & $41.9 \%$ \\
Media & Facebook & 200 & $53 \%$ \\
Sosial & Instagram & 371 & $95.4 \%$ \\
& Twitter & 142 & $36.5 \%$ \\
& WA/Line & 326 & $83.8 \%$ \\
& Youtube & 74 & $19 \%$ \\
& Dll & 68 & $17.5 \%$ \\
Durasi & 1-3 Jam & 61 & $15.7 \%$ \\
& 3-6 Jam & 163 & $42.7 \%$ \\
& 6-8 Jam & 66 & $16.9 \%$ \\
& >8 Jam & 96 & $24.7 \%$ \\
\hline
\end{tabular}

Berdasarkan tabel 2 menggunakan analisis deskriptif, maka menunjukkan bahwa analisis mean mendapatkan nilai mean skor tertinggi pada traits Machiavellianism yakni dengan nilai mean sebesar 21.09 dan skor terendah terletak pada traits psychopathy yaitu sebesar 11.20 yang terlihat dalam tabel dibawah ini:

Tabel 2. Deskripsi Penelitian Secara Keseluruhan 


\begin{tabular}{lcl}
\hline Dark Triad & Mean & SD \\
\hline Machiavellianism & 21.09 & 4.17 \\
Narcissm & 20.80 & 3.53 \\
Psychopthy & 11.20 & 3.33 \\
\hline
\end{tabular}

Berdasarkan tabel 3. presentase kategori variabel machiavellianism, $76.16 \%$ responden memiliki traits machiavellianism sedang, dilanjutkan $15.80 \%$ memiliki traits machiavellianism tinggi, dan $8.03 \%$ berada pada traits rendah.

Tabel 3. Rentang Nilai dan Kategorisasi Machiavellianism

\begin{tabular}{cccc}
\hline Kategori & Rentang Nilai & Frekuensi & Persentase $\%$ \\
\hline Tinggi & $25.26 \leq \mathrm{X}$ & 61 & $15.80 \%$ \\
Sedang & $16.92 \leq \mathrm{X}<$ & 294 & $76.16 \%$ \\
& 25.26 & & \\
\multirow{2}{*}{ Rendah } & $\mathrm{X} \leq 16.92$ & 31 & $8.03 \%$ \\
& Total & 386 & $100 \%$ \\
\hline
\end{tabular}

Berdasarkan Tabel 4. presentase kategori variabel Narcissism, $68.92 \%$ responden memiliki traits Narcissism sedang, dilanjutkan $16.32 \%$ memiliki traits Narcissism rendah, dan $14.76 \%$ berada pada traits tinggi.

Tabel 4. Rentang Nilai dan Kategorisasi Narcissism

\begin{tabular}{lccl}
\hline Kategori & Rentang Nilai & Frekuensi & Persentase\% \\
\hline Tinggi & $\mathrm{X} \geq 24.33$ & 57 & $14.76 \%$ \\
Sedang & $17.27 \leq \mathrm{X}<$ & 266 & $68.92 \%$ \\
& 24.33 & & \\
\multirow{5}{*}{ Rendah } & $\mathrm{X} \leq 17.27$ & 63 & $16.32 \%$ \\
& Total & 386 & $100 \%$ \\
\hline
\end{tabular}

Berdasarkan tabel 5. presentase kategori variabel psychopathy, $70.98 \%$ responden memiliki traits psychopathy sedang, dilanjutkan $15.02 \%$ memiliki traits psychopathy tinggi, dan $13.98 \%$ berada pada traits psychopathy rendah.

Tabel 5. Rentang Nilai dan Kategorisasi Psychopathy

\begin{tabular}{lccl}
\hline Kategori & RentangNilai & Frekuensi & Persentase $\%$ \\
\hline Tinggi & $\mathrm{X} \geq 14.53$ & 58 & $15.02 \%$ \\
Sedang & $7.87 \leq \mathrm{X}<$ & 274 & $70.98 \%$ \\
& 14.53 & & \\
Rendah & $\mathrm{X} \leq 7.87$ & 54 & $13.98 \%$ \\
& Total & 386 & $100 \%$ \\
\hline
\end{tabular}

\section{Traits}

pertama

yakni

machiavellianism, seseorang yang memiliki kepribadian machiavellianism merupakan orang yang rendah dalam locus of control dan mereka fokus pada pencapaian tujuan dan harus menang dengan cara apa pun (Jones \& Pauhlus 2009). Machiavellianism juga seorang yang cerdik, dalam meraih apapun mereka akan melakukan berbagai cara untuk mencapai tujuan mereka dengan tidak memandang baik atau buruk perbuatannya. Dalam konteks menggunakan media sosial, mereka biasanya tidak memperlihatkan profil asli yang sebenarnya tentang diri sendiri karena senang untuk memanipulasi, menipu orang lain dan berbohong. individu dengan machiavellianism yang tinggi cenderung menginginkan orang untuk tidak tahu informasi tentang diri mereka sendiri, juga berkaitan erat dengan kepribadian antisosial, yang saat ini diklasifikasikan sebagai gangguan mental (Lyons, M 2019). Mereka lebih suka berkomunikasi secara online, dimana mereka dapat memanipulasi orang lain dengan mudah.

Spain, Harms \& Lebreton (2013) mengatakan bahwa individu yang berkepribadian machiavellianism cenderung 
sebagai individu yang bersifat manipulatif dan ketika menipu atau membohongi orang lain maka yang dirasakan ialah perasaan senang.. Hasil penelitian menunjukkan $15.80 \%$ memiliki kepribadian machiavellianism tinggi. Hal ini berbahaya bagi para pengguna media sosial saat ini, terutama pada remaja.

Hasil penelitian menemukan $14.76 \%$ berada pada kepribadian narcissism tinggi. Traits yang kedua dalam kepribadian triad dark adalah narcissism. Kepribadian narcissism memiliki ciri-ciri yaitu kurangnya rasa empati, berani, dan tidak memiliki perasaan dengan yang lainnya (Lyons, 2019). Hal ini membuktikan bahwa seseorang yang narsis dalam menggunakan media sosial cenderung tidak menggunakan perasaannya serta berani untuk menyakiti orang lain. Hal ini senada dengan beberapa penelitian sebelumnya yaitu oleh Vander Molen, R. J., Kaplan, S., Choi, E., \& Montoya, D. (2018) \& Geel, V.M, Goemans, A, Toprak, F \& Paul Vedder (2016) yang menjelaskan bahwa kepribadian narsisme berpengaruh terhadap penggunaan media sosial.

Banyak aktivitas yang bisa dilakukan pada media sosial, salah satu kegiatan yang dilakukan adalah swafoto. Individu yang melakukan swafoto dimedia sosial salah satu tujuannya adalah untuk mendapatkan pujian, mencari tanda jempol atau like dari pengguna lainnya yang menimbulkan rasa kepuasan pada individu tersebut (Mulawarman \& Nurfitri, 2017). Apabila keadaan sebaliknya, individu tersebut merasa tidak dihargai di lingkungan dunia maya terutama di media sosial

Traits ketiga dalam dark triad personality adalah Psychopathy. Hasil penelitian ini menunjukkan $15.02 \%$ memiliki kepribadian psychopathy tinggi.
Individu yang memeiliki kepribadian ini cenderung menjadi pribadi yang menuruti kata hati secara spontan, impulsif dan kurangnya empati dalam bersikap. Individu ini kurang memiliki rasa takut dan cemas seperti kebanyakan individu lainnya. Dalam menggunakan media sosial, tentu saja kepribadian ini membuat indiviu sesuka hati dan tanpa memikirkan perasaan pengguna lain dalam menggunakan media sosial, seperti berkomentar secara spontan, menyebarkan berita tanpa berfikir panjang dan lainnya.

Berdasarkan dari tiga kepribadian gelap yakni machivellianism, narcissm dan psychopathy, maka dalam penelitian ini nilai mean yang tertinggi adalah kepribadian machiavellianism. Preotiuc-Pietro, D., Carpenter, J., Giorgi, S., \& Ungar, L. (2016) menjelaskan bahwa penelitian tentang dark triad personality semakin diminati karena aktivitas di media sosial semakin meningkat. Melihat rutinitas masyarakat belakangan ini khususnya remaja yang semakin hari tidak dapat terpisahkan dari media sosial dan dengan beberapa permasalahan dimedia sosial yang tidak ada habisnya maka seharusnya permasalahan ini menjadi perhatian khusus.

Islam memandang kepribadian merupakan ciri umum yang dapat dibedakan antara manusia dengan makhluk lain (Hasanah, 2018). Kepribadian dalam perspektif islam merupakan integrasi dalam kalbu (hati), akal serta nafsu yang membentuk perilaku manusia (Hasanah, 2018). Banyak ayat-ayat di dalam Al-Qur'an yang menjelaskan tentang kebebasan manusia dalam berkepribadian. Ayat-ayat yang membahas hal tersebut diantaranya QS AlKahfi ayat 29, QS Al-Baqarah ayat 256, QS Al-Kafirun ayat 6 yang membahas tentang kebebasan dalam memilih agama, selanjutnya 
QS Al-balad ayat 8-10 yang menjelaskan tentang kebebasan dalam memilih salah satu dari dua jalan, memilih antara kebaikan atau jalan keburukan. Oleh karena itu, kebebsan yang telah dijelaskan ini manusia dituntut untuk mengupayakan perilakunya dengan baik.

Hasanah (2018) menjelaskan bahwa dalam perspektif islam terdapat tiga dinamika kepribadian, yakni kepribadian ammarah, kepribadian lawwamah serta kepribadian muthmainnah. Dari tiga dinamika kepribadian yang dijelaskan, maka dalam kepribadian gelap atau dark triad personality merupakan kepribadian yang didominasi pada tingkah laku negatif, sehingga dalam perspektif islam termasuk dalam kepribadian ammarah yang berarti individu tersebut cenderung pada tabiat jasad dan mengejar prinsip kenikmatan.

Menurut Gumiandari, S (2011) kepribadian ammarah yaitu kepribadian yang cenderung dominan oleh nafsu, selanjutnya dibantu oleh akal serta kalbu. Pada kepribadian ini menarik kalbu manusia untuk dapat melakukan perbuatan yang buruk sehingga melakukan keburukan atau tingkah laku yang tercela, hal ini sesuai dengan ciriciri kepribadian gelap. Jones dan Figueredo (2013) mengungkapkan bahwa dark triad personality memiliki sifat antagonis yaitu perasaan tidak berperasaan dan manipulasi. Orang-orang dengan kedudukan tinggi pada karakteristik dark triad berpotensi mengancam kesejahteraan orang lain. Penelitian juga menunjukkan bahwa kecenderungan individu ini untuk menggertak orang lain (Baughman, Dearing, Giammarco, \& Vernon, 2012), menunjukkan perilaku pemeliharaan hubungan negatif (Jonason \& Kavanagh, 2010; Smith et al., 2014). Jones dan Paulhus (2010) mengemukakan bahwa individu ini juga cenderung melakukan perilaku agresi.

Kepribadian ammarah dalam
penjelasan diatas dimaknai sebagai kepribadian yang tidak lagi memiliki sifatsifat seperti manusia sebab rasa kemanusiaanya telah hilang. Orang-orang yang memiliki kepribadian ini cenderung untuk dapat merusak dirinya dan orang lain. Kepribadian ini ditentukan oleh dua hal, yaitu: (1) syahwat, maksudnya adalah dimana individu ini menginginkan birahi, ingin tau dan suka ikut campur urusan orang lain, dan sebagainya; (2) ghadah yang selalu menginginkan tamak, serakah, mencekal, berkelahi, ingin menguasai orang, keras kepala, sombong, angkuh, dan sebagainya.

Penggunaan media sosial salah satu tujuannya adalah sebagai sarana untuk berkomunikasi dan terhubung satu sama lain sehingga dapat menjalin silaturahmi. Dalam melakukan proses komunikasi perlu memperhatikan etika agar komunikasi yang terjalin berjalan efektif dan lancar, harapannya adalah agar apa yang disampaikan dapat diterima dengan baik oleh orang lain. Etika-etika tersebut seperti mengatakan perkataan yang benar, lemah lembut serta mudah untuk dipahami (Cartono, 2018). Hal ini dilakukan agar terhindar dari perpecahan dan permusuhan atau bahkan memutuskan hubungan sosial.

Islam melarang umatnya untuk memutuskan hubungan sosial. Salah satu ayat yang menjelskan tentang keberadaan media social salah satu ayat sering digunakan adalah Surat Al-Hujurat ayat 13.

"Hai manusia, sesungguhnya Kami menciptakan kamu dari seorang laki-laki dan seorang perempuan dan menjadikan kamu berbangsa -bangsa dan bersuku-suku supaya 
kamu saling kenal-mengenal. Sesungguhnya orang yang paling mulia diantara kamu disisi Allah ialah orang yang paling taqwa diantara kamu. Sesungguhnya Allah Maha Mengetahui lagi Maha Mengenal."

Berdasarkan dari kutipan ayat diatas maka jelaslah bahwa dengan media sosial, maka perbedaan-perbedaan yang ada di masyarakat seperti yang disebutkan dalam surat al-Hujurat ayat 13 dapat berbaur, bersatu dan menciptakan kesejahteraan bersama bukan menunjukkan perilaku yang negatif seperti agresi yang dijelaskan berdasarkan dari ciri-ciri dark triad personality tersebut yang pada akhirnya terjadi perpecahan dan permusuhan.

\section{SIMPULAN}

Hasil penelitian menunjukkan $15.80 \%$ memiliki kepribadian machiavellianism tinggi, $14.76 \%$ berada pada kepribadian narcissism tinggi serta hasil penelitian ini juga menunjukkan $15.02 \%$ memiliki kepribadian psychopathy tinggi. Berdasarkan hasil analisis nilai mean dari faktor kepribadian berdasarkan terori dark triad personality maka dapat ditarik kesimpulan, yaitu secara umum memiliki nilai mean tertinggi pada kepribadian machiavellianism dengan nilai mean sebesar 21.09 dan skor terendah terletak pada kepribadian psychopathy yaitu sebesar 11.20.

Berdasarkan hasil penelitian yang telah dilakukan, maka penulis mengajukan beberapa saran, yaitu bagi peneliti selanjutnya yang ingin melakukan penelitian yang serupa dapat menambahkan variabel psikologis lainnya diluar variabel yang telah digunakan dalam penelitian ini. Peneliti selanjutnya juga dapat mengambil populasi yang lebih besar sehingga generalisasi penelitian ini akan lebih luas. Lebih lanjut, dapat dilakukan penelitian dengan meenggunakan metode kualitatif untuk mendapatkan gambaran yang mendalam mengenai fenomena penggunaan media sosial yang marak terjadi pada saat ini.

Saran kepada Pihak sekolah dapat melakukan pembekalan atau pendekatan kepada remaja agar tidak terjebak dengan perilaku negatif dalam menggunakan media sosial misalnya dengan ceramah, diskusi pembinaan akhlak dan moral ataupun pengajian remaja.

Dalam penelitian ini ditemukan bahwa dari tiga kepribadian gelap yakni machivellianism, narcissm dan psychopathy, yang memiliki nilai mean tertinggi adalah pada kepribadian machiavellianism maka berpeluang besar dalam bersikap manipulatif di media sosial. Saran yang penulis berikan untuk pemerintah yakni sebaiknya dapat mengantisipasi, meningkatkan pelayanan serta menindaklanjuti secara tegas terhadap penyalahgunaan yang terjadi di media sosial.

\section{DAFTAR PUSTAKA}

APJII. (2019). Penetrasi \& Profil Perilaku Pengguna Internet Indonesia Tahun 2018. Apjii, 51. Retrieved from www.apjii.or.id.

Blair, R. J. R. (2013). The neurobiology of psychopathic traits in youths. Nature Reviews Neuroscience, 14(11), 786-799. https://doi.org/10.1038/nrn3577.

Bohang, F.K (2018). Berapa Jumlah Pengguna Internet Indonesia?", diakses dari:

https://tekno.kompas.com/read/2018/02/ 22/16453177/berapa-jumlah-penggunainternet indonesia. pada tanggal 10 Juni 2019. 
Bathia, M., Rajpoot, M., \&Dwivedi, V. (2016). Pattern of internet addiction among adolescent school students of a North Indian city. International Journal of Community Medicine and Public Health, 3(9), 2459-2463.

Cartono. (2018). Komunikasi islam dan interaksi media sosial. ORASI Jurnal Dakwah dan Komunikasi, 9(2). 59-74.

Fuchs, C. (2014). Social Media a Critical Introduction. Los Angeles: SAGE Publication, Ltd.

Goodboy, A. K., \& Martin, M. M. (2015). The personality profile of a cyberbully: Examining the Dark Triad. Computers in Human Behavior, 49, 1-4. https://doi.org/10.1016/j.chb.2015.02.05 2

Gumiandari, S. (2011). Kepribadian manusia dalam perspektif psikologi islam (Telaah kritis atas psikologi modern). Holistik, 12 (01).259-296.

Hasanah, M. (2015). Dinamika kepribadian menurut psikologi islam. Jurnal Ummul Qura 6(2) 110-124. https://doi.org/10.1080/10911359.2015. 1059165

Indirwan. (2018). TIPE KEPRIBADIAN REMAJA AKTIF PADA MEDIA SOSIAL (Studi Komparatif Siswa SMA dan MA) SOSIAL (Studi Komparatif Siswa SMA dan MA). 1-109.

Jones, D. N., \& Paulhus, D. L. (2014). Introducing the Short Dark Triad (SD3): A Brief Measure of Dark Personality Traits. Assessment, 21(1), 28-41. https://doi.org/10.1177/10731911135141 05.

Kircaburun, K., Jonason, P. K., \& Griffiths, M. D. (2018). The Dark Tetrad traits and problematic social media use: The mediating role of cyberbullying and cyberstalking. Personality and Individual Differences, 135(June), 264269.

https://doi.org/10.1016/j.paid.2018.07.03 4

Lyons, M. (2019). The dark triad of personality Narcissism, machiavellianism, and psychopathy in everyday life. Academic Press.

Mulawarman, M., \& Nurfitri, A. D. (2017). Perilaku Pengguna Media Sosial beserta Implikasinya Ditinjau dari Perspektif Psikologi Sosial Terapan. Buletin Psikologi, 25(1), 36-44. https://doi.org/10.22146/buletinpsikologi .22759

O'Boyle, E. H., Forsyth, D. R., Banks, G. C., \& McDaniel, M. A. (2012). A metaanalysis of the Dark Triad and work behavior: A social exchange perspective. Journal of Applied Psychology, 97(3), 557-579.

https://doi.org/10.1037/a0025679.

Preotiuc-Pietro, D., Carpenter, J., Giorgi, S., \& Ungar, L. (2016). Studying the Dark Triad of Personality through Twitter Behavior. Proceedings of the 25th ACM International on Conference on Information and Knowledge Management - CIKM '16. doi:10.1145/2983323.2983

Quarshie, H. O., Mis, M. B. A., \& Cyber, P. G. (2012). The Impact of Computer Technology on the Development of Children in Ghana. 3(5), 717-722.

Ramsay, M. (2012). Machiavellianism. Encyclopedia of Applied Ethics, (1991), 1-9. https://doi.org/10.1016/B978-0-12373932-2.00270-2 
Reed, K. P., Cooper, R. L., Nugent, W. R., \& Russell, K. (2016). Cyberbullying: A literature review of its relationship to adolescent depression and current intervention strategies. Journal of Human Behavior in the Social Environment, 26(1), 37-45. https://doi.org/10.1080/10911359.2015.1 059165

Spain, S. M., Harms, P., \& Lebreton, J. M. (2014). The dark side of personality at work. Journal of Organizational Behavior, 35(SUPPL.1). https://doi.org/10.1002/job.1894

van Geel, M., Toprak, F., Goemans, A., Zwaanswijk, W., \& Vedder, P. (2017). Are Youth Psychopathic Traits Related to Bullying? Meta-analyses on CallousUnemotional Traits, Narcissism, and Impulsivity. Child Psychiatry and Human Development, 48(5), 768-777. https://doi.org/10.1007/s10578-0160701-0

Vander Molen, R. J., Kaplan, S., Choi, E., \& Montoya, D. (2018). Judgments of the Dark Triad based on Facebook profiles. Journal of Research in Personality, 73(November), 150-163. https://doi.org/10.1016/j.jrp.2017.11.010

Wright, M. F., Huang, Z., Wachs, S., Aoyama, I., Kamble, S., Soudi, S., Shu, C. (2020). Associations between cyberbullying perpetration and the dark triad of personality traits: the moderating effect of country of origin and gender. Asia Pacific Journal of Social Work and Development, $\quad 00(00), \quad 1-15$. https://doi.org/10.1080/02185385.2020.1 788979 